\title{
Chromosome instability as an indicator of malignant progression in laryngeal mucosa.
}

Citation for published version (APA):

Veltman, J. A., Bot, F. J., Huynen, F. C., Ramaekers, F. C. S., Manni, J. J., \& Hopman, A. H. N. (2000). Chromosome instability as an indicator of malignant progression in laryngeal mucosa. Journal of Clinical Oncology, 18, 1644-51. https://doi.org/10.1200/JCO.2000.18.8.1644

Document status and date:

Published: 01/01/2000

DOI:

10.1200/JCO.2000.18.8.1644

Document Version:

Publisher's PDF, also known as Version of record

\section{Please check the document version of this publication:}

- A submitted manuscript is the version of the article upon submission and before peer-review. There can be important differences between the submitted version and the official published version of record.

People interested in the research are advised to contact the author for the final version of the publication, or visit the DOI to the publisher's website.

- The final author version and the galley proof are versions of the publication after peer review.

- The final published version features the final layout of the paper including the volume, issue and page numbers.

Link to publication

\footnotetext{
General rights rights.

- You may freely distribute the URL identifying the publication in the public portal. please follow below link for the End User Agreement:

www.umlib.nl/taverne-license

Take down policy

If you believe that this document breaches copyright please contact us at:

repository@maastrichtuniversity.nl

providing details and we will investigate your claim.
}

Copyright and moral rights for the publications made accessible in the public portal are retained by the authors and/or other copyright owners and it is a condition of accessing publications that users recognise and abide by the legal requirements associated with these

- Users may download and print one copy of any publication from the public portal for the purpose of private study or research.

- You may not further distribute the material or use it for any profit-making activity or commercial gain

If the publication is distributed under the terms of Article $25 \mathrm{fa}$ of the Dutch Copyright Act, indicated by the "Taverne" license above, 


\title{
Chromosome Instability as an Indicator of Malignant Progression in Laryngeal Mucosa
}

\author{
By Joris A. Veltman, Fredrik J. Bot, Ference C. Huynen, Frans C.S. Ramaekers, Johannes J. Manni, \\ and Anton H.N. Hopman
}

\begin{abstract}
Purpose: Routine histologic examination cannot predict whether premalignant laryngeal lesions will progress toward invasive growth. The acquisition of changes in chromosome constitution has been suggested to be essential for driving tumor progression by enhancing mutagenic mechanisms. The aim of the present study was to determine whether chromosomal changes occur in the subsequent stages of early laryngeal carcinogenesis and, if so, whether these changes can be of prognostic value.

Materials and Methods: Numerical aberrations for chromosomes 1 and 7 were detected in tissue sections from archival material using an improved in situ hybridization protocol. In total, eight benign laryngeal lesions, 37 premalignant laryngeal lesions, and 16 specimens containing histologically normal epithelia adjacent to laryngeal squamous cell carcinomas were studied. Both the histologic and the cytogenetic classifications were correlated with progression to laryngeal cancer.
\end{abstract}

$\mathrm{T}$ HE GENERATION OF abnormal chromosome numbers (aneuploidy) is a key characteristic of most solid tumors, including head and neck squamous cell carcinomas (HNSCCs). ${ }^{1-3}$ Although the patterns of chromosomal alterations among HNSCCs differ widely, intratumoral heterogeneity seems to be limited: Identical patterns of chromosomal alterations, including extensive chromosomal copy number imbalances and chromosome polysomy, have recently been detected by us in macroscopically distinct areas of individual HNSCC specimens. ${ }^{4}$ It can be deduced from these results that abnormal chromosome patterns are present in an early stage of head and neck carcinogenesis and remain relatively stable during clonal expansion. It has been suggested that the development of aneuploidy, indicative for genetic instability, is crucial for cells to progress through

From the Departments of Otorhinolaryngology and Head and Neck Surgery, and Pathology, University Hospital Maastricht, and Department of Molecular Cell Biology and Genetics, University of Maastricht, Maastricht, the Netherlands.

Submitted March 8, 1999; December 15, 1999.

Address reprint requests to Johannes J. Manni, MD, Department of Otorhinolaryngology and Head and Neck Surgery, University Hospital Maastricht, PO Box 5800, 6202 AZ Maastricht, the Netherlands; email j.j.manni@kno.a2m.nl.

(C) 2000 by American Society of Clinical Oncology.

0732-183X/00/1808-1644
Results: No evidence for chromosome alterations was obtained in the control group, nor in histologically normal epithelia adjacent to laryngeal squamous cell carcinomas, nor in all but one hyperplastic lesion ( $n=$ 11 ). In contrast, 14 of 15 dysplastic lesions and nine of 11 carcinomas-in-situ contained numerical chromosomal aberrations. Tetrasomy was present in the majority of the dysplastic lesions. An unstable chromosome content (indicated by the presence of chromosome imbalances and/or polyploidization) in the premalignant lesion strongly predicted its malignant progression.

Conclusion: Our results show that laryngeal tumor development involves chromosome tetraploidization. The further change from a stable to an unstable chromosome constitution is of importance for malignant progression.

J Clin Oncol 18:1644-1651. () 2000 by American Society of Clinical Oncology.

the initial stages of the carcinogenic process by enhancing mutagenic mechanisms. ${ }^{5-8}$ Although there are some reports on the presence of chromosomal aberrations in premalignant head and neck epithelia, no detailed information is available on the complexity of the chromosome patterns in these epithelia. ${ }^{2,9}$

In this study, the in situ hybridization (ISH) technique using chromosome-specific probes was performed on a clinically and histologically well-defined series of premalignant lesions of the larynx. In addition, extensive stretches of histologically normal epithelia adjacent to laryngeal squamous cell carcinomas (LSCCs) were investigated in order to find out whether numerical chromosomal aberrations can be detected in these carcinogen-exposed areas, as reported by others. ${ }^{2}$ The improved protocol was applied to thin tissue sections and allowed a direct coupling of the genetic information to the histopathologic phenotype. Based on previous studies with HNSCC, DNA probes directed against the centromeric regions of chromosomes 1 and 7 were chosen. ${ }^{2-4,10}$ Using these techniques, we were able to study the presence of aneuploidy, chromosomal copy number imbalances, and polyploidization in different histologic stages of laryngeal preneoplasia. This allowed us to draw conclusions about the sequence of changes in the chromosome content that occur during early laryngeal carcinogenesis. In addition, the chromosome classification of premalignant lesions was correlated to clinical follow-up in order 
to find out whether the different steps in chromosome aneuploidization were indicative for malignant transformation.

\section{MATERIALS AND METHODS}

\section{Patient Material}

Forty-two formalin-fixed, paraffin-embedded specimens were available from the laryngeal lesions of 33 patients. All of these specimens were obtained by microlaryngeal surgery. In this procedure, the lesions were completely removed and no further therapeutic intervention was applied. From six of these patients, subsequent biopsy specimens containing premalignant laryngeal lesions were included. As a control group, benign vocal cord polyps of 10 patients were included; these were innocent lesions like singer's nodules. In addition, from each of nine patients with LSCC who underwent total laryngectomy, two formalin-fixed, paraffin-embedded specimens containing histologically normal epithelia either adjacent to laryngeal carcinomas or at the margin of resection were used. From all of these specimens, a hematoxylin-eosin-stained serial section was thoroughly reviewed by an experienced pathologist (F.J.B.) and classified as normal, hyperplastic, dysplastic, carcinoma-in-situ (CIS), or infiltrative carcinoma according to Friedmann. ${ }^{11}$ Hyperplasia is defined as keratosis and acanthosis with, at most, slight atypia of the basal cell layer. Dysplastic lesions show, in addition, more than just slight individual cell atypia, increasing keratosis, and sometimes parakeratosis. CIS is characterized by, in addition to the above, increasing, often full-thickness cell atypia, loss of polarity, frequent mitoses, and the absence of infiltrative growth. Normal epithelium is regular, nonkeratinizing squamous epithelium without the features mentioned above. The lesions of the study group generally did not show significant heterogeneity; however, when present, the lesions were classified according to the most atypical region of the specimen. These criteria provide a separation of mild, moderate, and severe dysplastic lesions. For practical reasons, we combined the mild and moderate dysplastic lesions. Severe dysplasia was considered equal to CIS. Laryngeal papillomas were not included in this study. This subdivision is in accordance with clinical practice, ie, as a rule, mild and moderate dysplastic lesions are only monitored clinically, whereas severe dysplasia as a rule leads to complete removal of the lesion or other appropriate clinical interventions.

\section{ISH}

ISH was essentially performed using a recently optimized protocol. ${ }^{12}$ Briefly, after deparaffinization, $4-\mu \mathrm{m}$-thick sections were pretreated with $85 \%$ formic acid containing $0.3 \% \mathrm{H}_{2} \mathrm{O}_{2}$, followed by incubation at $80^{\circ} \mathrm{C}$ in $1 \mathrm{~mol} / \mathrm{L}$ sodium thiocyanate. After digestion with pepsin from porcine stomach mucosa (800 to $1,200 \mathrm{U} / \mathrm{mg}$ protein; Sigma Chemical Co, St Louis, MO) at a concentration of $4 \mathrm{mg} / \mathrm{mL}$ in $0.02 \mathrm{~N} \mathrm{HCl}$, individual sections were hybridized using a centromere-specific probe for either human chromosome 1 or 7, both labeled with biotin-11-dUTP (Boehringer, Mannheim, Germany). ${ }^{13}$ Immunochemical detection of hybridization products was performed by a standard avidin-biotin complex procedure. Signals were developed using diaminobenzidine/ $\mathrm{H}_{2} \mathrm{O}_{2}$; sections were counterstained with hematoxylin and mounted in Entellan (Merck, Darmstadt, Germany).

\section{Evaluation of ISH Results}

Evaluation was performed qualitatively by three investigators (J.A.V., F.C.H., and A.H.N.H.) by analyzing in detail the histopatho- logically normal and premalignant laryngeal epithelia, scoring for the presence of nuclei with aberrant copy numbers, studying the distribution of these nuclei, and determining the highest copy number. In all evaluations, strict criteria for the classification of individual nuclei were applied. ${ }^{14}$ On the basis of this evaluation, lesions were classified as either disomic, trisomic, tetrasomic, or polysomic based on the maximum chromosome copy number present in the lesion (two, three, four, or $>$ four, respectively). All lesions classified as genetically aberrant contained a significant number of aneusomic cells per microscopic image field $(\times 40)$. All histologic areas classified as genetically normal contained only sporadic nuclei exhibiting more than two ISH signals. In these cases, the neighboring cells were disomic. Whether or not the rare aneusomic cells should be considered as genetically unstable or result from a nuclear overlap leading to misclassification cannot be determined. In addition to this qualitative analysis, a quantitative analysis was performed by counting the chromosome copy number in 400 nuclei per histologic area. On the basis of these results, ISH spot-count distribution patterns were obtained for each specimen with each chromosome probe and the chromosome index (CI) was calculated (CI was defined as the mean number of chromosome copies per nucleus).

\section{Statistical Analysis}

Statistical analysis was performed using Statistical Package for the Social Sciences software version 7.5 (SPSS, Inc, Chicago, IL). For this analysis, only patients with no previous history of LSCC were included. The two-sided Fisher's exact test was used to investigate whether there was a significant difference in progression to invasive cancer in (a) different histologic subgroups and (b) groups with distinct patterns of chromosomal aberrations. The limit for significance was set at $P=.05$. In addition, the Kaplan-Meier method was used for plotting a cancer-free survival curve. The log-rank test was used for survival analysis.

\section{RESULTS}

Using the ISH protocol described, discrete hybridization signals were obtained in combination with the retention of a proper nuclear and tissue morphology in eight (80\%) of 10 control specimens, in 16 (89\%) of 18 biopsy specimens from histologically normal epithelia in the surroundings of laryngeal cancers, and in 37 (88\%) of the 42 premalignant lesions. Figure 1 illustrates typical ISH results for normal epithelia and different premalignant stages of laryngeal epithelia. Because of nuclear truncation in the tissue sections, many nuclei in the normal epithelia exhibited fewer than two chromosome-specific signals. Therefore, a normalvalue study was performed to determine the ISH distribution pattern in normal laryngeal epithelia.

\section{ISH on Normal Laryngeal Epithelia}

Normal epithelia from eight patients with benign vocal cord lesions showed zero, one, or two signals per nucleus for both chromosomes 1 and 7. No nuclei with more than two signals were identified by detailed analysis of the entire epithelia of these eight cases, nor were differences observed between the ISH patterns of chromosomes 1 and 7. As an example, Fig 1A shows a detail of the ISH pattern observed 


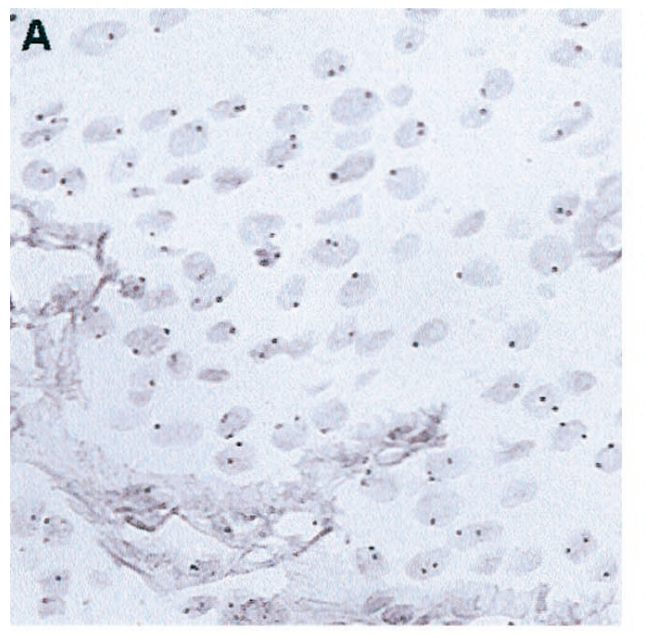

B
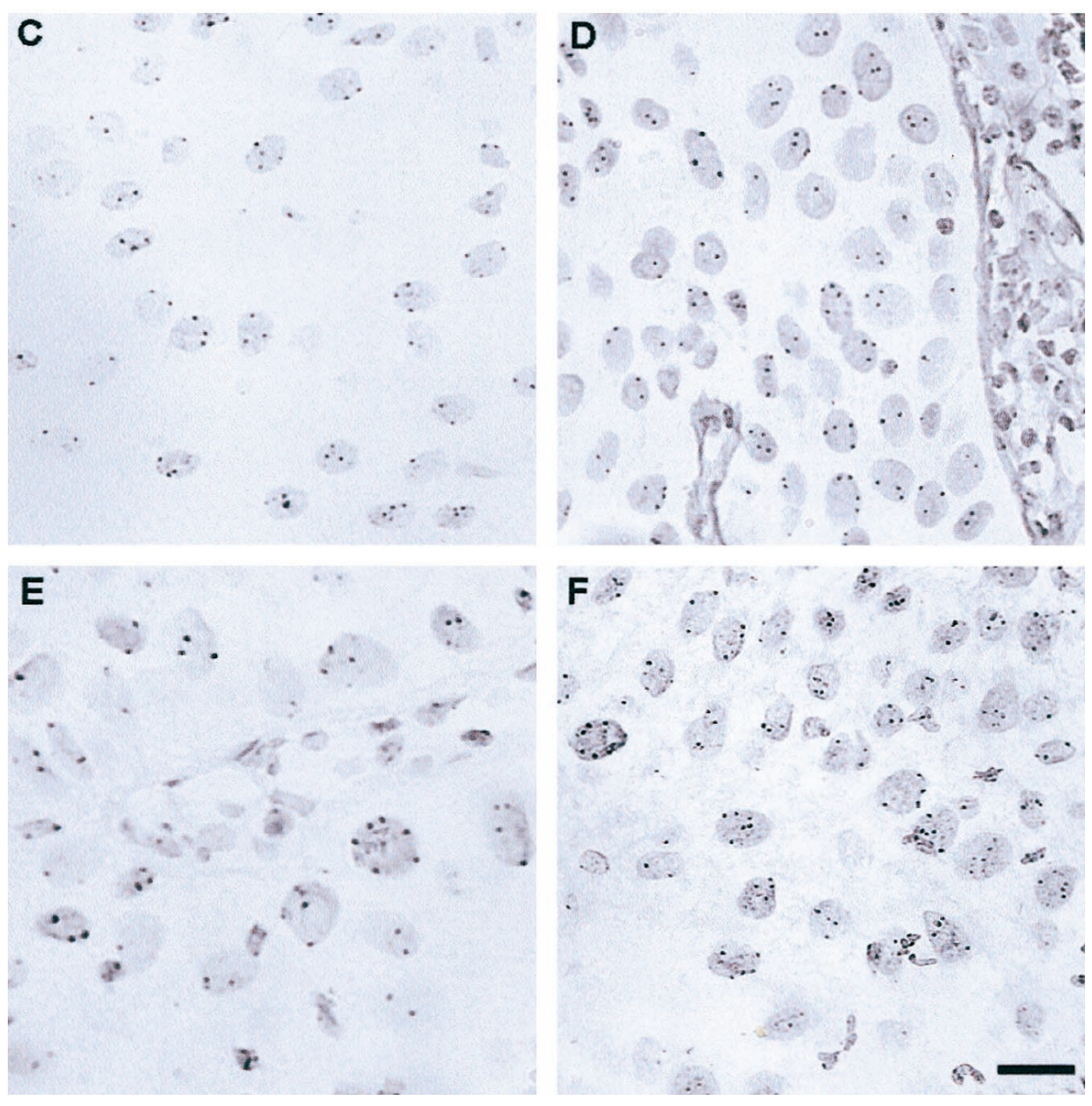

Fig 1. Examples of ISH analyses on 4- $\mu$ m-thick sections of histopathologically normal, hyperplastic, and premalignant laryngeal epithelia. Chromosome 1 analysis of (A) normal epithelium and (D) a dysplastic lesion. Chromosome 7 analysis of $(B, C)$ two hyperplastic lesions and (E, F) two CIS lesions. Scale bar, $10 \mu \mathrm{m}$. for chromosome 1 in normal laryngeal epithelia. In addition, Fig 2A shows the mean ISH distribution patterns and SDs for chromosomes 1 and 7 in these specimens. On the basis of these results, the mean number of chromosome copies per nucleus (CI) was calculated to be 1.4 for both chromosomes (range, 1.3 to 1.5 ). Using the mean value plus three times 
Fig 2. Mean ISH distribution patterns plus SDs in 4- $\mu \mathrm{m}$-thick sections (chromosome 1, घ; chromosome 7, $\square)$ from (A) epithelia from benign laryngeal lesions and (B) histologically normal epithelia adjacent to LSCCs. ISH distribution pattern of (C) a hyperplastic lesion classified as disomic for chromosomes 1 and 7, (D) a dysplastic lesion with tetrasomy for both chromosomes, (E) a CIS with chromosome copy number imbalances, and (F) a CIS with polyploidization.
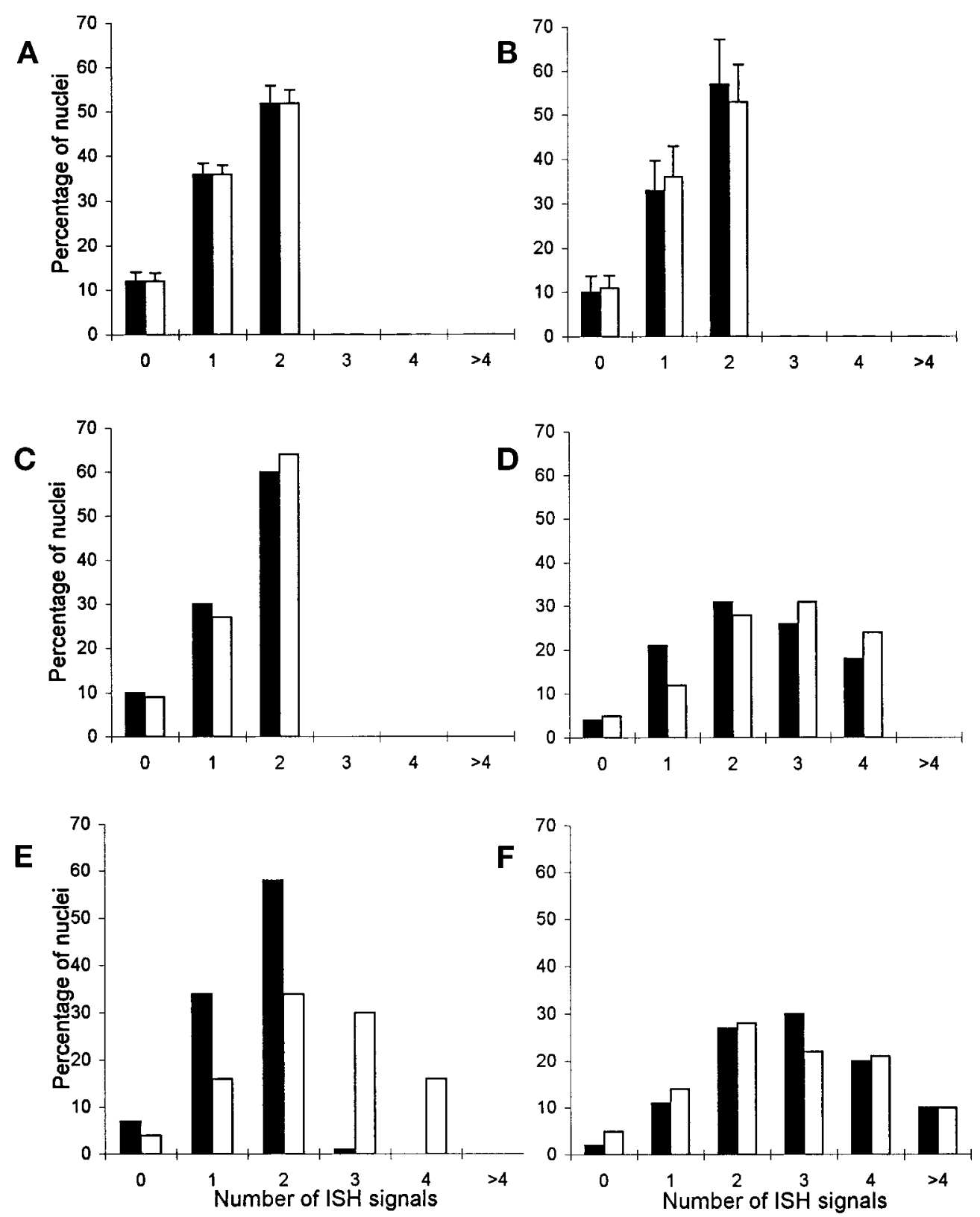

the SD, a CI of 1.7 is highly suggestive for gain of chromosomes.

\section{ISH on Normal Epithelia Adjacent to LSCCs}

Extensive areas of histologically normal epithelia adjacent to LSCCs $(n=8)$ and at the margins of resection of the same cases $(n=8)$ were analyzed both qualitatively and quantitatively. In this group, no nuclei with three or more chromosome copies were identified in either the qualitative or the quantitative analysis, nor were differences observed between the ISH patterns of chromosomes 1 and 7. The mean ISH distribution patterns and SDs for chromosomes 1 and 7 are shown in Fig 2B. Comparable ISH patterns were observed in normal epithelia adjacent to LSCCs and in normal epithelia at the margins of resection of the same tumors (results not shown). The mean CI values of both chromosomes, 1.5 for chromosome 1 (range, 1.3 to 1.6) and 1.4 for chromosome 7 (range, 1.2 to 1.6), were also comparable in this group. 
Table 1. Overview of the Qualitative Classification of the ISH Results in Normal and (Pre)Malignant Laryngeal Epithelia

\begin{tabular}{|c|c|c|c|c|c|c|c|c|c|c|}
\hline \multirow[b]{3}{*}{ Histology } & \multirow{2}{*}{\multicolumn{2}{|c|}{$\begin{array}{l}\text { Disomy for Chromosomes } \\
\qquad 1 \text { and } 7^{*}\end{array}$}} & \multicolumn{8}{|c|}{ Aneusomy for Chromosomes 1 and/or $7 \dagger$} \\
\hline & & & \multirow{2}{*}{$\begin{array}{l}\text { Total No. of } \\
\text { Specimens }\end{array}$} & \multirow{2}{*}{$\begin{array}{c}\text { \% of } \\
\text { Specimens }\end{array}$} & \multicolumn{2}{|c|}{$\begin{array}{l}\text { Tetrasomy } \\
\text { for } 1 \text { and } 7\end{array}$} & \multicolumn{2}{|c|}{$\begin{array}{c}\text { Imbalanced Copy } \\
\text { Numbers for } \\
1 \text { and } 7 \neq\end{array}$} & \multicolumn{2}{|c|}{$\begin{array}{l}\text { Polysomy for } \\
1 \text { and/or } 7 \S\end{array}$} \\
\hline & $\begin{array}{l}\text { Total No. of } \\
\text { Specimens }\end{array}$ & $\%$ & & & No. & $\%$ & No. & $\%$ & No. & $\%$ \\
\hline Normal control epithelia $(n=8)$ & 8 & 100 & 0 & 0 & \multicolumn{2}{|c|}{-} & \multicolumn{2}{|c|}{-} & \multicolumn{2}{|c|}{ - } \\
\hline Normal epithelia adjacent to LSCCs $(n=16)$ & 16 & 100 & 0 & 0 & \multicolumn{2}{|c|}{-} & & & \multicolumn{2}{|c|}{-} \\
\hline Hyperplasia $(n=11)$ & 10 & 91 & 1 & 9 & \multicolumn{2}{|c|}{-} & 1 & 9 & \multicolumn{2}{|c|}{-} \\
\hline Dysplasia $(\mathrm{n}=15)$ & 1 & 7 & 14 & 93 & 7 & 46 & 3 & 20 & 4 & 27 \\
\hline $\operatorname{CIS}(\mathrm{n}=11)$ & 2 & 18 & 9 & 82 & 2 & 18 & 2 & 18 & 5 & 46 \\
\hline $\operatorname{LSCC} \|(n=16)$ & 4 & 25 & 12 & 75 & 3 & 19 & 4 & 25 & 5 & 31 \\
\hline
\end{tabular}

*No evidence of nuclei with more than two ISH signals for both chromosomes.

†Containing multiple nuclei with more than two ISH signals for one or both chromosomes.

₹As evidenced by comparing the ISH results of chromosomes 1 and 7 in identical histologic areas of serial sections.

$\S$ Containing multiple nuclei with more than four ISH signals for one or both chromosomes.

||Selected from previously published data from our group. ${ }^{4,10}$

\section{ISH on Hyperplastic and Premalignant Laryngeal Epithelia}

On the basis of the qualitative analysis, the 37 lesions classified as hyperplastic, dysplastic, and CIS were genetically classified as disomic, trisomic, tetrasomic, or polysomic for chromosomes 1 and 7 (summarized in Table 1). An ISH pattern identical to that of the normal laryngeal epithelia was obtained in 10 hyperplastic lesions (Fig 1B). In these specimens, only sporadic nuclei exhibiting more than two ISH signals were identified after detailed analysis by three observers. In contrast, one hyperplastic lesion contained an area of approximately 300 nuclei with trisomy for chromosome 7 (Fig 1C), whereas no numerical aberrations were detected in the same area for chromosome 1. Chromosomal aberrations (ie, trisomy, tetrasomy, or polysomy) were detected in 14 of 15 dysplasia lesions and in nine of 11 CIS. Taking the nuclear truncation into consideration, it seemed that all nuclei within these lesions contained aberrant chromosome copy numbers. Nuclei located in the basal cell layer contained the same pattern of chromosomal aberrations as the other cell layers. Not only were nuclei with three or four ISH signals frequently observed (Fig 1D), but in some cases, nuclei with six to eight signals, indicating polyploidization, were clearly present (Fig $1 \mathrm{E}$ and $1 \mathrm{~F}$ ). In addition, imbalances in the copy numbers of chromosomes 1 and 7 were frequently observed by comparing the hybridization results of the two different probes in the same histologic area in serial sections. Histologically normal or hyperplastic epithelia, often present adjacent to an aneusomic dysplastic lesion or CIS, were never shown to contain nuclei with aberrant copy numbers for both chromosomes 1 and 7 (results not shown).
In order to validate the qualitative classification, and to obtain detailed information on the presence of chromosome imbalances and polyploidization, the ISH results of 22 lesions were further quantified by counting the chromosome copy number in 400 nuclei per specimen. Lesions classified by the qualitative approach as disomic for either chromosome 1 or 7 showed an ISH pattern similar to the pattern obtained for these chromosomes in the normal epithelia (Fig 2C). In contrast, all lesions classified as aneusomic for chromosome 1 and/or 7 revealed an aberrant ISH pattern (Fig 2D, 2E, and 2F). The percentage of nuclei with aberrant chromosome copy numbers ranged from $28 \%$ to $65 \%$ in these lesions. In all cases, evidence for the existence of both chromosome copy number imbalances and polyploidization in these premalignant lesions confirmed the qualitative analysis (eg, Fig 2E and 2F). Taking the results of both chromosomes together, the CIs of the lesions classified as disomic by the qualitative approach varied between 1.3 and 1.6 (mean CI, 1.4), whereas the CIs of the lesions classified as aneusomic varied between 1.9 and 2.9 (mean CI, 2.5).

From six cases included in this study, subsequent biopsy specimens taken from the same laryngeal location and containing premalignant lesions, were analyzed by ISH. Although the time interval between different biopsies was 2 to 4 years in some of these cases, a remarkable stability in the chromosome constitution was observed. Tetrasomy for the chromosomes 1 and 7 was observed in subsequent biopsies of two cases, whereas polysomy for chromosome 1 and/or 7 was detected in subsequent biopsies of three other cases. For only one case was a change detected from disomy for chromosomes 1 and 7 in the first two biopsies to tetrasomy for both chromosomes in the third biopsy. 


\section{Correlation Among Histology, Chromosome \\ Classification, and Progression to Laryngeal Cancer}

Ten of 25 assessable cases developed LSCC. The median follow-ups of the progressive and the nonprogressive groups were 72 (range, 25 to 149 months) and 61 months (range, 18 to 99 months), respectively. All LSCCs developed within 47 months after diagnosis of the first premalignant lesion.

There was a significant difference in clinical follow-up between patients with hyperplastic lesions and patients with dysplastic lesions or CIS $(P=.01)$. No significant difference in progression was observed between patients with dysplastic lesions and patients with CIS $(P>.05)$. Also no significant difference in progression was observed between the group of patients with lesions without evidence of chromosomal abnormalities and the group of patients with chromosomal abnormalities $(P>.05)$. However, within the group of patients with aneusomic lesions, a significant difference in progression was observed between patients with lesions containing tetrasomy for both chromosomes and patients with lesions containing chromosome copy number imbalances and/or chromosome polysomy $(P=.03)$.

The time to cancer development from the baseline biopsy was significantly shorter in the group with unstable chromosome content (ie, chromosome copy number imbalances and chromosome polysomy) than in the group with stable chromosome content (ie, disomy and tetrasomy for both chromosomes) $(P=.027$ by the log-rank test; Fig 3$)$.

\section{DISCUSSION}

In this study, the chromosomal constitution of premalignant laryngeal lesions was investigated by applying the ISH technique to paraffin sections. The use of a strongly improved ISH protocol, resulting in an improved retention of tissue morphology, sharply localized ISH signals, and a reduced minor binding of the DNA probes proved to be essential for a detailed analysis of both normal and premalignant laryngeal epithelia. ${ }^{12}$ The use of a suboptimal protocol easily leads to misclassification. In our study, both qualitative and quantitative analyses were performed, while strict evaluation criteria were applied for the classification of individual nuclei. ${ }^{14}$

Our results show no numerical aberrations for chromosomes 1 and 7 in control laryngeal epithelia, while histologically normal epithelia adjacent to laryngeal tumors showed normal chromosome content. This finding is in contrast with data in the literature reporting low percentages of nuclei with numerical aberrations for chromosomes 7 and 17 in normal epithelia adjacent to head and neck cancers. ${ }^{2}$ Based on the data presented in the underlying study and our

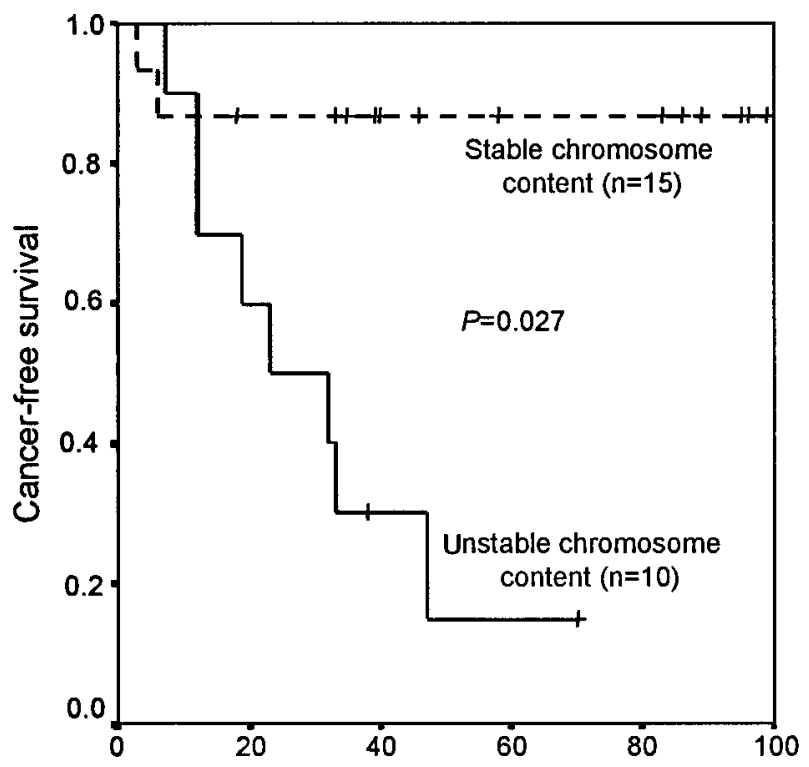

Time in months

Fig 3. Cancer-free survival in patients with stable and unstable chromosome content. Kaplan-Meier curves are shown for 25 patients. Data on patients who did not develop LSCC were censored in the analysis. In the group of patients with stable chromosome content, the lesions were disomic or tetrasomic for chromosomes 1 and 7. In the group of patients with unstable chromosome content, the lesions had chromosome copy number imbalances and were polysomic for chromosomes 1 and 7 . The difference in cancer-free survival time was tested using the log-rank test.

recent work on resection margins from oral squamous cell carcinomas (van der Toorn PP et al, manuscript submitted for publication), we conclude that numerical aberrations for chromosomes 1 and 7 are not detected in histologically normal epithelia adjacent to HNSCCs. Although all kinds of (epi)genetic changes might occur randomly in this carcinogen-exposed tissue, our data indicate that these changes do not cause major alterations in the chromosome content, such as chromosome copy number changes. Numerical chromosome alterations were detected only in expanded cell populations that had accumulated extensive genetic changes and which in most cases were histologically altered to at least mild degrees of dysplasia (discussed below). Similar results were recently described for morphologically normal cervical epithelia adjacent to cervical intraepithelial neoplasia. ${ }^{15}$

No numerical chromosomal aberrations were found in 10 of 11 laryngeal hyperplastic lesions. Interestingly, in one hyperplastic lesion, an area with trisomy for chromosome 7 was observed. Trisomy for chromosome 7 was also identified in two dysplastic lesions and one CIS lesion included in this series. Trisomy for chromosome 7 has been described in 
many tumor types, often as the sole chromosomal aberration, and has therefore been interpreted as a primary change in cancer development. ${ }^{1}$ In contrast to the ISH results for hyperplastic lesions, $93 \%$ of the dysplastic lesions and $82 \%$ of the CIS contained numerical aberrations for one or both of the chromosomes examined, percentages that are comparable to that for HNSCC. ${ }^{4}$ This shows that the acquisition of abnormal chromosome numbers is an early event in laryngeal carcinogenesis and can be detected in nearly all lesions with dysplasia. Expansion of these aneusomic cell populations was evidenced by the fact that the entire dysplastic or CIS lesion contained nuclei with abnormal chromosome numbers, whereas adjacent nondysplastic areas did not contain chromosome aneusomy.

Tetrasomy for both chromosomes 1 and 7, indicating a more or less balanced tetraploid chromosome status, was present in a considerable number of dysplastic lesions (46\%), whereas only a minority of the CIS lesions (18\%) had a balanced chromosome status. These results provide support to the theory that tetraploidization takes place as one of the first steps in the change of the genomic content, and they indicate that this change is correlated with the histologic change from hyperplasia to dysplasia. The cells containing these excessive chromosome numbers will then become cytogenetically unstable, both losing and gaining chromosomes randomly over the course of successive cell divisions. ${ }^{16}$ Chromosome copy number imbalances and/or polyploidization, indicative of an overall chromosomal instability, indeed seemed to be more common in CIS lesions, although they were also found in a number of dysplastic lesions. The identification of these complex chromosome patterns in premalignant stages of laryngeal carcinogenesis strongly resembled the chromosome patterns identified by us in HNSCC.,

Interestingly, progression to invasive cancer was significantly more common in patients with lesions contain- ing these chromosome imbalances or polyploidization as compared with patients with lesions with a balanced tetrasomic chromosome status. In contrast to these genetic subgroups, there was no significant difference in clinical follow-up between dysplastic lesions and CIS lesions. In our opinion, this is the first report demonstrating a correlation between tumor development and the presence of specific chromosomal abnormalities in a premalignant lesion. These data strongly indicate that the acquisition of chromosomal instability is crucial for cells to progress through the initial stages of laryngeal carcinogenesis. In this respect, our data complement a genetic progression model for head and neck carcinogenesis showing an increased loss of heterozygosity of specific chromosome regions with histologic progression, predominantly at the transition from hyperplasia to dysplasia. ${ }^{17}$ It might be expected that both genomic changes, ie, loss of heterozygosity and chromosome instability, are essential for driving tumor progression. This hypothesis is supported by a study showing that HNSCCs with a marked loss of heterozygosity are mostly DNAaneuploid. ${ }^{18}$

In conclusion, this study showed that the correlation of numerical chromosome aberrations with morphologic parameters helped to define sequences of genetic events that occur in premalignant laryngeal lesions. The chromosome patterns observed in these lesions strongly suggest that most laryngeal tumors develop via a genetic pathway involving chromosome tetraploidization, followed by the acquisition of genetic instability, as evidenced by chromosome copy number imbalances and chromosome polyploidization. The acquisition of genetic instability seemed to be associated with progression to invasive growth. The identification of these chromosome patterns can easily be applied as an additional tool in the diagnosis of these preinvasive lesions.

\section{REFERENCES}

1. Mitelman F: Catalog of Chromosome Aberrations in Cancer (ed 5). New York, NY, Wiley-Liss, 1994

2. Voravud N, Shin DM, Ro JY, et al: Increased polysomies of chromosomes 7 and 17 during head and neck multistage tumorigenesis. Cancer Res 53:2847-2883, 1993

3. Soder AI, Hopman AHN, Ramaekers FCS, et al: Distinct nonrandom patterns of chromosomal aberrations in the progression of squamous cell carcinomas of the head and neck. Cancer Res 55:50305037,1995

4. Veltman JA, Hopman AHN, van der Vlies SA, et al: Doubletarget fluorescence in situ hybridization distinguishes multiple genetically aberrant clones in head and neck squamous cell carcinoma. Cytometry 34:113-120, 1998

5. Lengauer C, Kinzler KW, Vogelstein B: Genetic instability in colorectal cancers. Nature 386:623-626, 1997
6. Orr-Weaver TL, Weinberg RA: A checkpoint on the road to cancer. Nature 392:223-224, 1998 (editorial)

7. Shackney SE, Shankey TV: Common patterns of genetic evolution in human solid tumors. Cytometry 29:1-27, 1997

8. Lengauer C, Kinzler KW, Vogelstein B: Genetic instabilities in human cancers. Nature 396:643-649, 1998

9. Lee JS, Kim SY, Hong WK, et al: Detection of chromosomal polysomy in oral leukoplakia, a premalignant lesion. J Natl Cancer Inst 85:1951-1954, 1993

10. Veltman JA, Hopman AHN, Bot FJ, et al: Detection of chromosomal aberrations in cytologic brush specimens from head and neck squamous cell carcinoma. Cancer 81:309-314, 1997

11. Friedmann I: Precursors of squamous cell hyperplasia, in Ferlito A (ed): Surgical Pathology of Laryngeal Neoplasms. London, United Kingdom, Chapman \& Hall, 1996, pp 107-122 
12. Hopman AHN, Ramaekers FCS: Processing and staining of cell and tissue material for interphase cytogenetics, in Robinson P (ed): Current Protocols in Cytometry. New York, NY, John Wiley \& Sons Inc, 1998, chapter 8.5.1-8.5.22

13. Willard H, Waye J: Hierarchical order in chromosome-specific human alpha satellite DNA. Trends Genet 3:192-198, 1987

14. Hopman AHN, van Hooren E, van de Kaa CA, et al: Detection of numerical chromosome aberrations using in situ hybridization in paraffin sections of routinely processed bladder cancers. Mod Pathol 4:503-513, 1991
15. Bulten J, Poddighe PJ, Robben JCM, et al: Interphase cytogenetic analysis of cervical intraepithelial neoplasia. Am J Pathol 152:495-503, 1998

16. Shackney SE, Smith CA, Miller BW, et al: A. model for genetic evolution of human solid tumors. Cancer Res 49:3344-3354, 1989

17. Califano J, van der Riet P, Westra W, et al: Genetic progression model for head and neck cancer: Implications for field cancerization. Cancer Res 56:2488-2492, 1996

18. El Naggar A, Hurr K, Batsakis JG, et al: Sequential loss of heterozygosity at microsatellite motifs in preinvasive and invasive head and neck squamous carcinoma. Cancer Res 55:2656-2659, 1995 